\title{
Spotted around the web: Antipsychotic prescriptions, global autism prevalence, mouse genetic drift
}

\author{
BY JILL ADAMS
}

29 OCTOBER 2021

WEEK OF OCTOBER $25^{\mathrm{TH}}$

\section{Research roundup}

- One in four children with tuberous sclerosis complex may have autism; those not diagnosed often still have autism traits. Annals of Neurology

- Cannabis preparations appear to alleviate repetitive grooming behavior and anxiety in a mouse model of autism, suggesting potential roles for both cannabidiol and tetrahydrocannabinol. Translational Psychiatry

- Whether a child in a case study has a girl's or a boy's name has no effect on how likely specialists are to identify that child as having autism. Journal of Autism and Developmental Disorders

- Children diagnosed with autism by age 2 and a half may show more improvement in social behavior than those diagnosed at older ages. Autism

- Policies intended to temper antipsychotic prescribing in children have reduced the total number of prescriptions, but half of the remaining prescriptions are for unapproved indications. BMC Psychiatry

- By monitoring 17 body parts during walking, an automated system can detect differences among people with various neurological conditions, including autism and fragile $X$ syndrome. Scientific Reports

- For every 10,000 people, there are 59 cases of autism in Europe, 86 in North America and 47 in Oceania, according to median autism prevalence estimates derived from studies spanning the years 1993 to 2019. European Journal of Public Health

- Laboratory mouse colonies may have experienced genetic drift during COVID-19 lockdowns, potentially affecting research results. Spectrum has previously covered how a mouse's genetic background can skew analyses of behavior and biology. Lab Animal 


\section{Spectrum | Autism Research News}

https://www.spectrumnews.org

\section{Science and society}

- Many U.S.-based parks and nature preserves have begun to offer more accommodations for autistic people, including trained park personnel and designated low-sensory areas. National Geographic

Quiet spaces: Parks have improved accessibility to become autism-friendly.

Lisa Winner

- Jill Sanghvi has earned her Ph.D. after conducting qualitative interviews with autistic people and using their words, organized into free verse, to write her dissertation. The Daily Courier

- Science organizations from around the globe have agreed upon eight principles to reform scientific publishing, including open access and rigorous peer review. International Science Council

- Robert Chapman, who studies the philosophy of neurodiversity, discusses a new way of thinking about function and dysfunction in an interview with psychiatrist Awais Aftab. Psychiatric Times

- Michael Rutter, who worked at the Institute of Psychiatry, King's College London in the United Kingdom for 55 years and has been called the "father of child psychiatry," died last week at age 88. King's College London 